\title{
Microalbuminuria and Serum Cystatin C: Biomarkers for Early Detection of Kidney Injury in Children with Obesity
}

\author{
Om P. Mishra ${ }^{1}$ (D) $\cdot$ Rajniti Prasad ${ }^{1}$ \\ Received: 16 September 2020 / Accepted: 5 October 2020 / Published online: 13 October 2020 \\ (C) Dr. K C Chaudhuri Foundation 2020
}

Obesity in children, has become a global epidemic in addition to metabolic syndrome. The latter is characterized by the presence of central obesity, dyslipidemia, hypertension and glucose intolerance and an increased risk of type 2 diabetes mellitus (type 2DM) in later life. It has been an established fact that obesity is associated with increased risk of kidney injury in children [1]. The effect of body mass index on the risk of end-stage kidney disease in a large cohort of population showed that there is an association between the baseline body mass index and the risk of chronic kidney disease [2]. There is gradual onset of kidney disease in obesity which is initially asymptomatic. Therefore, reliable biomarkers are needed for early detection and prevention. The biomarkers should be like that they can be easily measured, remain stable in urine or blood for considerable time, unaffected by chemical composition of fluid and have high validity and reproducibility. It can be albumin, cystatin C, $\beta 2$-microglobulin, interleukin-18, neutrophil gelatinase associated-lipocalin (NGAL), kidney injury molecule-1 (KIM-1), liver- type fatty acid binding protein (L-FABP) and N-acetyl-beta-D-glucosaminidase for early detection of kidney injury [3].

Microalbuminuria has been known to be an early marker of kidney injury in non-diabetic and diabetic patients. It is indicative of glomerular injury and found to be elevated in obese children than normal weight. Cystatin $\mathrm{C}$ is a marker of proximal tubular injury as it is filtered through glomerulus, metabolized in tubules and not being reabsorbed. Its production is relatively at a constant rate and correlates more closely with the glomerular filtration rate than the serum creatinine level, which is a late marker of kidney damage.

Om P. Mishra

opmpedia@yahoo.co.uk

1 Division of Pediatric Nephrology, Department of Pediatrics, Institute of Medical Sciences, Banaras Hindu University, Varanasi, India
The article of Oz-Sig et al. in this issue of journal studied microalbuminuria and serum cystatin $\mathrm{C}$ in 105 children with isolated obesity, metabolic syndrome and type $2 \mathrm{DM}$ with normal renal function [4]. It was found that mean values of both microalbuminuria and serum cystatin $\mathrm{C}$ were significantly elevated in type $2 \mathrm{DM}$ than metabolic syndrome. In addition, serum cystatin $\mathrm{C}$ level was also significantly raised in type $2 \mathrm{DM}$ in comparison to isolated obesity. The authors concluded that microalbuminuria and serum cystatin $\mathrm{C}$ may be estimated to screen for detection of early kidney damage in children having obesity and type 2 DM having normal glomerular filtration rates. However, the study has major limitations such as absence of normal healthy controls for comparison and there were lesser number of patients of type $2 \mathrm{DM}$ (only 6); limiting the generalizability of the findings. Further, post-treatment effect on the levels of biomarkers was also not assessed. Gayret et al. studied serum cystatin C, urinary NGAL, osteopontin, KIM-1 and matrix metalloproteinase-9 (MMP-9) and found significantly increased levels of serum cystatin $\mathrm{C}$ and urinary NGAL and osteopontin in obese than non-obese children with normal glomerular filtration rates, while urinary KIM-1 and MMP-9 remained unaltered [5]. Recently, Salman et al. reported serum cystatin $\mathrm{C}$ as an earlier biomarker than serum creatinine in the detection of impaired kidney function in obese children particularly in those with metabolic syndrome [6].

Thus, there is a link between obesity and kidney injury leading to chronic kidney disease and it is of major concern in pediatric population. Overall microalbuminuria and serum cystatin $\mathrm{C}$ can be used as reliable biomarkers for assessment of obesity related kidney damage. 


\section{Compliance with Ethical Standards}

Conflict of Interest None.

\section{References}

1. Gunta SS, Mak RH. Is obesity a risk factor for chronic kidney disease in children? Pediatr Nephrol. 2013;28:1949-56.

2. Hsu C, McCulloch CE, Iribarren C, Darbinian J, Go AS. Body mass index and risk for end-stage renal disease. Ann Intern Med. 2006;144:21-8.

3. Ding W, Mak RH. Early markers of obesity-related renal injury in childhood. Pediatr Nephrol. 2015;30:1-4.
4. Oz-Sig O, Kara O, Erdogan H. Microalbuminuria and serum cystatin $\mathrm{C}$ in prediction of early-renal insufficiency in children with obesity. Indian J Pediatr. 2020 (in press). https://doi.org/10.1007/s12098020-03294-z.

5. Gayret ÖB, Taşdemir M, Erol M, Nacaroğlu HT, Zengi O, Yiğit Ö. Are there any new reliable markers to detect renal injury in obese children? Renal Fail. 2018;40:416-22.

6. Salman DO, Şıklar Z, İlarslan ENC, Özçakar ZB, Kocaay P, Berberoğlu M. Evaluation of renal function in obese children and adolescents using serum cystatin $\mathrm{C}$ levels, estimated glomerular filtration rate formulae and proteinuria: which is most useful? J Clin Res Pediatr Endocrinol. 2019;11:46-54.

Publisher's Note Springer Nature remains neutral with regard to jurisdictional claims in published maps and institutional affiliations. 